\title{
CURANDEROS Y MÉDICOS ILUSTRADOS* LA CREACIÓN DEL PROTOMEDICATO EN VENEZUELA A FINALES DEL SIGLO XVIII
}

\author{
Emanuele Amodio \\ Escuela de Antropología, FACES, Universidad Central de Venezuela; y Dpto. de \\ Antropología, Instituto Venezolano de Investigaciones Científicas, Caracas, \\ Venezuela - Apartado 51088, Caracas 1050, Venezuela
}

\section{RESUMEN}

Con la definitiva ampliación del control del Estado sobre las profesiones liberales (al servicio de su «proyecto» ilustrado), la creación del Protomedicato en Caracas (1777) responde a la exigencia de reglamentar y ejercer un control político sobre el ejercicio de la medicina y organizar y determinar la formación de los médicos, eliminando posibles alternativas terapéuticas y profesionales.

\section{SUMMARY}

By the definitive amplification of the control of the State on the liberal professions (put to the service of his enlightened "projet"), the creation in Caracas of the Protomedicato (1977), responded to the demand of regulating and exercise a political control on the practice of the medicine; he aimed to organize and determine the information of the doctors, eliminating possible therapeutic and professionals options.

\section{INTRODUCCIÓN}

La historiografía de la medicina occidental, más que la de otros ámbitos, se caracteriza por su enfoque clásico, desarrollándose dentro de un marco evolucionista, con una parábola ascendente y homogénea. Los hechos parecen sucederse fuertemente encadenados los unos a los otros, desde el más simple al más complejo, mos-

\footnotetext{
* Una primera versión del presente estudio fue presentada en el Simposio internacional «La Ilustración en Hispanoamérica y España: convergencias y divergencias», realizado en Caracas en noviembre de 1990. Agradecemos al Dr. Manuel Lucena Giraldo la lectura crítica del texto.
} 
trando el recorrido lineal, artificialmente coherente, de un progresivo perfeccionamiento de los conocimientos $\mathrm{y}$, por consecuencia, de las prácticas médicas.

Particularmente, el siglo XVIII es presentado como el centro medular de la «evolución» de la medicina: la «razón» que derrota con sus «luces» las prácticas populares de carácter «mágico» y las concepciones filosóficas de orden médico.

Aunque en el siglo XVIII, de manera general, la investigación empírica y la naciente «clínica» se abren espacios en el contexto de la tradición médica clásica, debemos admitir la presencia de recorridos alternativos en el campo médico, al lado de rupturas y discontinuidades en el pretendido crecimiento homogéneo de la ciencia médica. Por otro lado, la pluralidad de grupos sociales estratificados de la sociedad europea y americana del siglo XVIII es atravesada por una multiplicidad de movimientos culturales de los cuales sólo en la actualidad podemos vislumbrar algunos.

Así, sin negar el valor de las reconstrucciones unilineales de la historia de la medicina, se hace necesaria una revisión en consideración de los nuevos datos que emergen de los archivos y, también, a través de la utilización de paradigmas historiográficos nuevos, donde se dé más espacio al análisis de las disconformidades de la realidad histórica.

El caso que vamos a describir y analizar, ocurrido en Caracas a finales del siglo XVIII, nos va a permitir aclarar una «contradicción» aparente del panorama médico de la época: en el contexto general de la reglamentación y fiscalización de las prácticas médicas (en América, así como en Europa), junto a la organización del «nuevo» saber médico y de su transmisión, en Caracas se autoriza la actividad de los curanderos cuyas prácticas eran oficialmente prohibidas por el Estado español.

Este evento menudo es índice de un fenómeno mucho más amplio de carácter europeo que en la segunda mitad del siglo XVIII intenta relativizar el pensamiento ilustrado en medicina, proponiendo una manera alternativa de considerar los hechos médicos y, por ende, poniendo en duda el paradigma cientificista ya ampliamente dominante en medicina así como en las distintas ramas de la «ciencia» ilustrada.

En pleno auge del nuevo pensamiento científico ilustrado, en Europa resurge una polémica entre «pensamiento científico» y «pensamiento mágico» que ya había interesado el nacimiento de la Ilustración. Se propone un «paradigma naturalista», frente al dominante «paradigma mecanicista» de interpretación de la realidad. El campo privilegiado de esta contraposicion, una vez más, es la medicina y, particularmente, el «saber práctico», inductivo, inherente a las propiedades curativas de las plantas, etc., frente al «saber científico», deductivo, del pensamiento médico ilustrado, ya caracterizado por el experimentalismo de la naciente Clínica. 


\section{CURANDEROS Y MÉDICOS ILUSTRADOS}

\section{LA MEDICINA ESPAÑOLA DEL SIGLO XVIII}

Superando el menosprecio hacia la Ilustración española, la historiografía moderna se ha abocado a la reconstrucción de la historia de un siglo que aparece cada día más complejo, impulsado en el caso español por movimientos renovadores a todos los niveles de la sociedad de la época ${ }^{1}$. Particularmente con Carlos III la política real hacia las disciplinas científicas impulsa la producción de instituciones capaces de dar respuestas a las nuevas exigencias del Estado en España y en las colonias americanas. El llamado «reformismo borbónico» es expresión de tales movimientos institucionales; es decir, el intento de institucionalizar y controlar las nuevas ciencias, al servicio del proyecto político del Estado. No hace falta referirse a las expediciones científicas del siglo XVIII para percibir el alcance global de este fenómeno.

Mientras que las universidades se mantienen en buena parte dentro de los moldes rígidos y escolásticos del siglo XVII, el nuevo saber ilustrado encuentra nuevos espacios de producción y trasmisión ${ }^{2}$. Es en el campo médico, tal vez, en el que la Ilustración española muestra su fuerza y su complejidad. Como escribe Emilio Quevedo, el proyecto ilustrado en medicina comprende:

«1) La modificación de los planes de estudio de medicina para formar médicos en el esquema de las ciencias útiles y de la medicina clínica, más apta a las necesidades del momento que la medicina galénica.

2) Crear centros de formación quirúrgica moderna, los colegios de cirugía, instituciones parauniversitarias organizadas desde la nueva perspectiva, en similar espíritu que el de las reformas de las facultades médicas.

3) Organizar los jardines botánicos para reformar la enseñanza de la farmacia...»»3.

Así que, en el plano institucional, asistimos al establecimiento de los colegios médicos y los de cirugía. Por lo que se refiere a los colegios de cirugía, el nacimiento de estas instituciones representa un evento sumamente importante: la cirugía, saber

1 Cfr. Esteva DE SAgreRA, J. (1986), «La polémica sobre la ciencia ilustrada a través de la obra de Proust y Feijoo», en FerRero, P. M. (1986), Actas del Simposio CCI. Aniversario nacimiento de Joseph Celestino Mutis, Cádiz.

2 Gregorio Marañon afirmaba: «Las Universidades en la primera mitad del siglo XVIII estaban en plena decadencia, y dentro de ellas era la Facultad médica la más afectada por la vacuidad y la garrulería de sus profesores...; natural que así fuera, porque la decadencia política y la pobreza del país tenían que repercutir especialmente sobre la ciencia» (en ARCHILA, R. (1961), Historia de la medicina, Caracas, p. 216).

3 QUEVEDO, E. (1993), «El conflicto entre tradiciones científicas modernas europeas y americanas en el campo de la medicina en la América Latina Colonial», en LAFUENTE, A.; ELENA, A., \& ORTEGA, M. L. (eds.), Mundialización de la ciencia y cultura nacional, Madrid, p. 273. 
práctico y empírico, despreciado por los «médicos hipocráticos», asume una importancia especial, sobre todo por su característica de respuesta inmediata y cotidiana a las necesidades de salud.

La polémica médicos/cirujanos puede considerarse uno de los campos de debate entre dos maneras diferentes de entender la formación de las figuras médicas y la ingerencia del Estado sobre la cuestión:

\footnotetext{
«Con respecto a la sanidad se inicia un plan de actuaciones múltiples: por una parte se incrementan los conocimientos científicos de los sanitarios en instituciones ajenas a la Universidad, mediante la creación del Colegio de Cirugía de Cádiz (1748). Esta actuación permite introducir aires nuevos en la docencia médica y contraponer un estilo más práctico y experimentalista, al caduco escolasticismo de las universidades; con su fundación se establece un modelo a imitar y se reaviva una inveterada polémica intelectual y administrativa. Los nuevos cirujanos no quieren someterse a la férula de las viejas corporaciones gremiales médicas y establecen una confrontación de la que resulta beneficiado el Protomedicato, comprometido con los intereses centralizadores de la dinastía, ayudado siempre por el consejo de Castilla. Esta polémica cirujanos-médicos, reflejo de la mas general entre tradicionalistas e ilustrados, va a ser reproducida por los boticarios tradicionales y los boticarios con formación botánica.»4.
}

Esta centralización de la administración sanitaria en España tiene en la institución del Protomedicato su eje central, constituyéndose como tribunal destinado a evaluar el saber médico de los «practicantes» de medicina y autorizarlos para el ejercicio de la profesión. En 1780 esta institución se especializará ulteriormente en Protomedicato, Protocirujanato y Protofarmaceuticato, aumentando así su alcance 5 .

Finalmente, para completar este panorama, deben ser citadas las Academias de Medicina que sustituyen, en cierta manera, a las universidades en el debate más teórico y, al mismo tiempo, son incentivo para la renovación de la formación de los médicos. También deben ser citadas las revistas médicas editadas por las «tertulias», de las cuales una de las más importantes fue la «Tertulia literaria médico-químicafísica», fundada en la Corte en 1732, amparada por el médico real José Cervi ${ }^{6}$.

${ }^{4}$ PUERTO SARMIENTO, F. J. (1988), La ilusión quebrada (Botánica, sanidad y política científica en la España Ilustrada), Madrid., p. 12. Sobre el mismo tipo de polémica en América, cfr. QUEVEDO, E. (1992), "Antecedentes de las reformas médicas del siglo XVIII y XIX en el Nuevo Reino de Granada. Una polémica entre médicos y cirujanos», en LAFUENTE, A. \& SALA CATALÁ (eds), Ciencia colonial en América, Madrid.

5 FÉBRES-CORDERO, F. (1987), Historia de la medicina en Venezuela y América, Caracas, pp. 337.

${ }^{6}$ GRANJEL, L. S. (1960), «Panorama de la medicina española durante el siglo XVIII», Revista de la Universidad de Madrid, IX (35), pp. 689-90. 


\section{CURANDEROS Y MÉDICOS ILUSTRADOS}

Todo este multiplicarse de instituciones fue producto directo del debate activo de médicos convencidos, de una manera u otra, de la necesidad de renovación de la medicina. Sobre este debate campea la figura de Feijoo (1676-1764). Aun no siendo médico, este fraile benedictino con su actitud «enciclopedista» se interesó profundamente en la medicina y supo suscitar con su «criticismo» un debate que se prolongará hasta el final del siglo XVIII. Toda su obra, desde el Teatro Crítico Universal hasta las Cartas Eruditas, fue destinada a combatir las «dudosas varias opiniones comunes» y tuvo un carácter eminentemente pedagógico y de divulgación científi$\mathrm{ca}^{7}$. Feijoo fue partidario de una medicina experimental, ello sin despreciar el saber popular cuando éste demostraba su utilidad. Sin embargo, el experimentalismo de Feijoo es de tipo particular: lejos de ser completamente metódico, se reduce a un «simple empirismo», basado en el sentido común 8 . Como escribe Corinne Zara Yahni, «la actitud de Feijoo es el reverso de la orientación concebida durante siglos anteriores por la alquimia, en la que la teoría no es confrontada con la realidad, trabajando de espaldas a los resultados. Ello explica el profundo desprecio con el que trata Feijoo la cuestión alquímica, sin reparar que sus recelos de las teorías le hacían tomar una postura inversa pero igualmente vulnerable.»9.

Es esta misma actitud «práctica» la que lo lleva a aceptar curaciones populares, cercanas a las mismas supersticiones que pretende combatir. Véase, por ejemplo, el capítulo sobre las «Virtudes nuevas de la piedra de serpiente», en sus Cartas Eruditas (Tomo. II, D9) 10.

La influencia del fraile benedictino fue enorme también porque supo, con su antimaterialismo, conjugar algunos aspectos de la Ilustración con el más tradicional catolicismo ${ }^{11}$. Entre sus críticos más importantes debe ser citado el doctor Martín Martínez, que acusa a Feijoo de contribuir a frenar la evolución de la medicina y que en 1748 dará su contribución a la evolución de la misma con la obra Medicina Scéptica.

A esta obra debe atribuirse una función importante en la transformación del «empirismo» superficial en «empirismo clínico y racional», aunque fuera de una postura sistemática ${ }^{12}$. La crítica de Martínez no se apunta sólo hacia los «médicos clásicos», con bases hipocráticas, sino que ataca también a los modernos impulsores de la latroquímica, «ciencia» constituida en sistema cerrado, basado sobre la física galileana. Entre los iatroquímicos se debe citar el médico aragonés Andrés Piquer

\footnotetext{
7 Cfr. AviLÉS, F. y otros (1982), Carlos III y fin del antiguo régimen, Madrid.

8 Maravall, J. A. (1964), «Feijoo el europeo, desde América». Revista de Occidente, diciembre, p. 354.

9 ZARA YAHNI, (1986), p. 129. (1986).

10 En ZARA YAHNI, (1986), «Aportación de Feijoo a la terapéutica del siglo XVIII», en FERRERo

11 Cfr. ESTEVA DE SAGRERA (1986), p. 124.

12 LÓPEZ PIÑERO, J. M. (1986), La ciencia en la historia hispánica, Barcelona, p. 52.
} 
(1711-1772) que, sin embargo, terminará adhiriéndose al «empirismo racional» de Martínez. Del Dictamen sobre reforma de estudios médicos en España (1768) del doctor Andrés Piquer, citamos un párrafo que resume el cuadro aquí delineado:

\begin{abstract}
«La medicina hoy en España no está en tanta decadencia como a los fines del siglo pasado y gran parte del presente. Hallábanse entonces preocupados los médicos, unos manteniendo tenazmente la enseñanza galénico-arábiga, otros embebidos de los sistemas modernos. Ya hoy, desengañados los más de los malos caminos que seguían, siguen el plan de la medicina verdadera, dedicados a entender y ejecutar sólo aquello que manifiesta y descubre la misma naturaleza.» ${ }^{13}$.
\end{abstract}

El carácter de esta época ilustrada, en el campo médico como en muchos otros, puede ser resumido por una frase del mismo Andrés Piquer: «Vale más una experiencia que cien razones y vale más una razón que cien autoridades.»14.

\title{
3. MÉDICOS CONTRA «PRÁCTICOS»
}

La progresiva institucionalización de la medicina es paralela a la profunda renovación de la misma. El «nacimiento de la clínica», como ampliamente ha estudiado Michel Foucault en Francia ${ }^{15}$, fue un fenómeno que involucró a toda Europa. La importancia atribuida a la práctica clínica permitía, en perspectiva, superar la dicotomía entre «saber práctico» (boticarios, cirujanos, etc.) y «saber teórico» (medicina clásica, aforismos de Hipócrates, etc.). Pero esto era posible sólo cuando los dos «saberes» eran comprobados por el método experimental y, para esto, será necesario acumular toda la experiencia del siglo XVIII.

Así, a lo largo del siglo XVIII, es posible detectar la existencia (claramente, no gremial) de grupos de «profesionales de la salud», caracterizados específicamente por sus ideas y prácticas médicas: los «clásicos», los «prácticos» y los «clínicos», los tres grupos bien contrapuestos entre sí.

La contraposición entre los «clínicos» y los «clásicos» es obvia: el saber «clínico» se contrapone al tradicional, cuyo origen es más filosófico que empírico. También la contraposición entre «clásicos» y «prácticos» resulta casi obvia: el saber cotidiano y popular, resultado de la experiencia, frente a la autoridad del saber de los pensadores clásicos, cuyas teorías médicas eran consideradas válidas a priori (Hipócrates, Galeno,

\footnotetext{
13 En Mindan, M. (1956), «Andrés Piquer y su contribución a la historia de la medicina», en Actas del XV Congreso Internacional de Historia de la Medicina, I, Madrid.

14 Idem.

15 FouCAult, M. (1986), El nacimiento de la Clínica, México.
} 


\section{CURANDEROS Y MÉDICOS ILUSTRADOS}

etc.). Mas interesante se presenta la relación entre médicos «clínicos» y médicos «prácticos», entre los cuales hay que incluir los curanderos populares, los boticarios y, en cierta medida, también los cirujanos (hasta, por lo menos, su revalorización oficial a mediados del siglo XVIII). Veamos las raíces de esta contraposición.

Durante la segunda mitad del siglo XVII, las creencias en los efectos de la «magia» habían menguado paulatinamente $y$, aunque la Inquisición continuaba activa, sus acusaciones se dirigían ya más hacia los «delitos» ideológicos y menos hacia los «pactos con el diablo» ${ }^{16}$.

La filosofía mecanicista, así como la caída de la teoría del «microcosmos» y la convicción de que el universo es regido por leyes inmutables, habían hecho tambalear la creencias mágicas ${ }^{17}$. Si a esta situación añadimos la progresiva especialización de los saberes y su misma institucionalización, resulta fácil entender el alejamiento paulatino de los grupos sociales dominantes de la cultura (y del saber) popular. Es decir, que la crisis de la magia del siglo XVII había interesado sobre todo a las élites y no a las masas populares. Escribe William Monter:

«Al lado del confesionalismo triunfante de los cincuenta años sucesivos al 1670 se produjo una separación muy clara y amplia en toda la Europa Occidental entre la cultura de las élites y la cultura popular. Los estudiosos recientes no están de acuerdo en atribuir "en primer lugar" la responsabilidad de este hecho a la intervención del Estado o en ver su causa en el adoctrinamiento religioso y en la modernización de la economía, pero todos convienen que para la fecha de 1750 la cultura de las élites se habia destacado de la cultura popular como nunca antes había acontecido.» ${ }^{18}$.

Aunque este proceso se da en manera menor en Italia y España, también aquí la tendencia se manifiesta ampliamente, particularmente en el campo médico ${ }^{19}$. Es en este contexto donde debe situarse la contraposición de los «médicos clínicos» a los «prácticos» (curanderos), los cuales son acusados de utilizar remedios populares y/o

16 Recordamos que las condenas contra médicos por parte de la Inquisición se dan hasta el final del siglo XVIII. Por ejemplo, el médico Proust fue condenado en España en 1800. Cfr. ESTEVA DE SAGRERA (1986), p. 124.

17 Cfr. ThOMAS, K. (1985), «L'eclisse della magia». Prometeo, 3 (7), Milano,p. 45.

18 MONTER, W. (1987), Riti, mitologia e magia in Europa all'inizio dell'età moderna, Bologna, p. 163.

19 Cfr. BonOMO, G. (1986), «Nueve ricerche sulla stregoneria», en CUCCU, M. y RossI, P. A. (1986), La strega, il teologo e lo scíenziato, Genova, p. 61. 


\section{EMANUELE AMODIO}

tradicionales que no tienen suficiente base «empírico-racional», y cuyas prácticas estarían todavía impregnadas de creencias mágicas ${ }^{20}$.

Sobre la base de estas consideraciones debe ser colocada la actitud pedagógica de los médicos clínicos y del mismo Feijoo. Como escribe Keith Thomas, «...la primera mitad del Setecientos asistió a notables esfuerzos para difundir el conocimiento entre el público analfabeto a través de manuales y enciclopedias, obras que a veces incluyen una actitud de agresiva hostilidad hacia las antiguas creencias mágicas» ${ }^{21}$. Esta difusión de «conocimientos» se realiza en buena parte a través de «cartillas» populares que, en lenguaje simple, intentan difundir los datos médicos de nuevos descubrimientos y combatir las supersticiones. Las «cartillas» eran vendidas en los mercados $\mathrm{y}$ ferias $\mathrm{y}$, a veces, eran comentadas en el lugar por el mismo vendedor ${ }^{22}$. Merece aquí ser citada, por su amplia difusión en España, la Cartilla nueva y útil y necesaria para instruirse las matronas, escrita por Antonio Medina en 1750, por mandato del Real Protomedicato ${ }^{23}$. De la misma manera, circulaban «recetarios» para uso de boticarios y particulares.

Es interesante anotar que esta circulación de material escrito de argumento médico terminaba favoreciendo la aparición de figuras particulares de curanderos, practicantes de una «medicina salvaje», fuera de las instituciones y en parte resultado de las nuevas teorías y prácticas médicas. Así, progresivamente, la vieja «curandera» y bruja popular, tan caricaturizada en las Memorias de la gitana Pepilla la Ezcurripa (1758) de don Cándido María Trigueros ${ }^{24}$, desaparece paulatinamente del escenario médico, para dejar paso a nuevos curanderos, contra los cuales se desata la oposición de los médicos oficialmente reconocidos por las instituciones del Estado (Universidades y Protomedicato, sobre todo). «El siglo de los grandes médicos, anota Foción Fébres Cordero, fue también el de los grandes charlatanes.» ${ }^{25}$.

En esta lucha contra los curanderos debe ser resaltada particularmente la obra del médico veronés José de Gazola: El mundo engañado de los falsos médicos ${ }^{26}$. En ésta, Gazola ataca también a los médicos «clásicos» proponiendo el uso de la «clínica»

\footnotetext{
${ }^{20}$ En este contexto es importante citar la creación de la «Cátedra de Clínica» en Madrid en 1795 y la Real Orden de 1795 a los Virreyes americanos para la recolección de obras médica para la biblioteca de la cátedra (AGS, Estado, 80, n. $^{\circ} 27$ ).

${ }^{21}$ THOMAS (1985), p. 46.

22 Cfr. BOURKE, P. (1980), Cultura popolare nell'Europa moderna, Milano.

${ }^{23}$ SÁNCHEZ MARTíN, A. (1958), El saber tocoginecológico en la medicina española de la primera mitad del siglo XVIII, 11 (2), Salamanca.

${ }^{24}$ Cfr. CARO BAROJA, J. (1986), Las brujas y su mundo, Madrid, p. 265.

${ }^{25}$ FÉBRES CORDERO (1987), pp. 227-238.

${ }^{26}$ Silva Álvarez, A. (1985), Situación médico-sanitaria de Venezuela durante la época del Libertador, Caracas, p. 51.
} 
como alternativa al saber de las «autoridades» (Hipócrates, Galeno, etc.), declarándose partidario de la renovación de los estudios médicos ${ }^{27}$.

Los boticarios tampoco se salvan de la crítica de los nuevos médicos. El ataque se refiere a la utilización de una «polifarmacia» utilizada sin bases experimentales. Escribe María del Carmen Vidal Casero:

\footnotetext{
«Este avance tuvo menos efectos de los que hubiera cabido esperar en la profesión médica como arte. El médico despreciaba las pretensiones del boticario y otros de prescribir a los enfermos o de enseñar nuevos métodos. Muchos recelos estaban justificados, porque los charlatanes abundaban y la ignorancia del origen de la enfermedad hacía del enfermo crédulo una fácil presa.» ${ }^{28}$.
}

El médico Félix Palacios fue uno de los mayores críticos de los «farmacéuticos». Su obra Palestra Pharmacéutica Chymico-Galénica alcanzó un éxito extraordinario a lo largo del siglo XVIII (9 ediciones y de la primera se distribuyeron 7.000 ejemplares) ${ }^{29}$, circulando también en América (la volveremos a encontrar en Caracas a finales del siglo XVIII).

Sin embargo, son estos mismos boticarios los que muchas veces contribuyen a la introducción de nuevas prácticas curativas, dando alternativas a las sangrías, purgantes y vomitivos abundantemente utilizados por los médicos clásicos. No se trata sólo de la introducción de remedios químico-galénicos, como la digital, la belladona, el cornezuelo de centeno y la quina, en la «Pharmacéutica» corriente; los boticarios introducen prácticas nuevas como la hidroterapia, la utilización del oxígeno y del magnetismo animal, los cuerpos electrolizados, etc. Se trata de formas de aceptación del naturalismo terapéutico, sobre todo a finales del siglo, dentro del contexto empírico-racional de la «clínica» ya dominante, aunque en relativa oposición teórica a ésta.

A este nuevo «naturalismo» se adhirieron un buen número de intelectuales médicos en toda Europa, detrás de las «ciencias» en auge como el mesmerismo, la rabdomancia y la fisiognómica. En verdad, en las últimas décadas del siglo XVII el paradigma mecanicista físico-matemático para explicar la realidad, entra parcialmente en crisis y es ésta la que favorece la producción de recorridos alternativos a la explicación de la enfermedad y la consecuente producción de nuevos tipos de curaciones. Escribe Vincenzo Ferrone:

27 AVILÉS (1982), p. 151.

28 VIDAL CASERO, M. C. (1986), «Cultura en el siglo XVIII. Desarrollo de Sociedades Científicas y Reales Academias», en FERRERO (1986), p. 71.

${ }^{29}$ PUERTO, M. J. \& SANZ DíAZ, L. (1986), «Las ideas científicas de Félix Palacios», en Ferrero (1986), p. 138. 


\begin{abstract}
«Probablemente tienen razón los que relacionan la vuelta de la magia como fenómeno de masa en la época de las revoluciones democráticas con las terribles incertidumbres sociales, políticas y económicas que todas las sociedades del Antiguo Régimen estaban atravesando. A los tiempos de carestía, revueltas y frustrantes desilusiones para aquéllos que habían creído poder cambiar una realidad profundamente injusta y refractaria al cambio, sólo podían corresponderse los primeros gérmenes de una cultura de la crisis, del repensamiento, de una búsqueda angustiada de recorridos diferentes del optimismo mecanicista propagado por los fautores del universo newtoniano y de aquel confiado deísmo que en ello había encontrado fundamento y legitimación.» ${ }^{30}$.
\end{abstract}

La adhesión al «naturalismo», en las últimas décadas del siglo XVIII, impulsa nuevamente aquella «curiosidad ilustrada» que ya había contagiado a todos los intelectuales de la época; mientras que asistimos a una revalorizacion de las «ciencias populares» y, por ende, de los mismos «médicos salvajes». Se vuelve a los fenómenos «mágicos», pero con una tensión especial de tipo indagatorio, donde la explicación puede ser encontrada fuera del ámbito cultural del fenómeno (la magia, el milagro, etc.), es decir en la riqueza misma de la naturaleza que, de esta manera, se presenta como un sistema abierto y múltiple, lleno de eventos imprevisibles, contra el universo cerrado de Galileo.

Sin embargo, esta nueva manera de percibir la realidad no debe ser considerada como una «patología de las luces», sino como una expresión de su misma riqueza. De otra manera, se corre el riesgo de limitar la Ilustración a un racionalismo reductivo, empobreciendo «...un fenómeno intelectual grandioso, rico en múltiples valencias y peculiaridades, capaz entonces de dar vida también a metamorfosis significativas como las producidas a finales del Setecientos» ${ }^{31}$.

\title{
4. LA MEDICINA EN CARACAS EN EL SIGLO XVIII
}

América participa en el movimiento de ideas de la Ilustración de manera directa. Esta participación no debe ser vista sólo como consecuencia (o efecto) del interés español para aplicar en las colonias ultramarinas los nuevos descubrimientos científicos a fines productivos o sus reformas administrativas y políticas. Hubo una participación activa y contemporánea al debate europeo y, también, en términos innovadores se discutió la necesidad de adaptar al «ambiente» local (natural y cultural) lo que el movimiento ilustrado producía en Europa. De hecho, como escribe Horacio

${ }^{30}$ FERRONE, V. (1989), I profeti dell'illuminismo, Bari, p. 107.

31 FERRONE, V. (1989), p. 10. 
Capel, «...en el siglo XVIII los americanos descubren que la ciencia europea no puede aplicarse sin más en el Nuevo Mundo.»32.

Esta participación directa de los eventos intelectuales europeos se realiza también a través de la presencia de «científicos» del Viejo Mundo que se establecen en América a lo largo del siglo XVIII. No se trata solamente de los funcionarios españoles, ligados a la administración, o de los científicos llegados con las expediciones botánicas, cartográficas, etc. En el caso de los médicos, encontramos un sinnúmero de profesionales franceses, alemanes, italianos, etc. que por variadas razones deciden establecerse en la América española y ejercer su profesión. Éstos contribuyen a la difusión en América de las nuevas ciencias europeas y asumen en las ciudades americanas el papel de impulsores de la renovación científica.

Veamos, antes que nada, cuál era la situación de salud en Caracas en la segunda mitad del siglo XVIII. En 1787 la ciudad de Caracas cuenta con 29.022 habitantes que se dividían, según el «Extracto de la población de la Provincia de Venezuela» formado por don José de Castro y Araoz, en los siguientes grupos: personas blancas: 8.315; gente de color libre, 12.073; indios libres, 490; esclavos 8.14433. Resulta evidente la preponderancia de las personas de color (libres y esclavos). Esta población sufre enfermedades endémicas, sobre todo epidemias de viruela, de las cuales la más trágica se dio en 1763-1764: «El incendio de las viruelas, refiere Foción FébresCordero, prende por todas partes hasta dejar la ciudad en un espantoso desierto» ${ }^{34}$. Solamente con la llegada a Venezuela del médico canario Juan Perdomo en 1766 se comenzará a utilizar la inoculación contra la viruela y así frenar las epidemias ${ }^{35}$.

La situación de salud también se agrava por la precaria terapéutica utilizada por los médicos. Pasa aquí lo mismo que en España: las curaciones se reducían fundamentalmente a sangrías, purgas, dietas, sudoríficos y enemas, según el modelo humoral clásico. Merece ser resaltado el uso, generalmente a nivel popular, de remedios de origen indígena: aceite de palo, bálsamo de Carora, cañafístola y tabaco.

Hay también otra razón que explica la mala situación de la salud de la mayor parte de la población caraqueña. Ricardo Archila afirma que «...Caracas gozó de asistencia médica en todo el transcurso del XVIII. Prácticamente, nunca llegaron a faltarles facultativos; al contrario hubo períodos, por ejemplo, en los años 1792 y

\footnotetext{
32 CAPEL, H. (1987), «Sobre ciencia hispana, ciencia criolla y otras ciencias europeas». Asclepio, XXXIX (2), Madrid, p. 227.

33 LEAL, H. (1961), «La aristocracia criolla venezolana y el código negrero de 1785». Revista de Historia, 6, Caracas, p. 66.

${ }^{34}$ FÉBRES-CORDERO (1987), p. 425.

35 Idem.
} 
1795, en que en relación con el número de sus habitantes, la proporción de galenos, si no óptima, por lo menos fue bastante satisfactoria»36.

Veamos más de cerca esta situación «satisfactoria». Según la «Relación a la Real Audiencia» de 1795 del Protomédico Felipe Tamariz, en este año había en Caracas diez médicos blancos, cinco cirujanos blancos y ocho cirujanos mulatos ${ }^{37}$. Considerando el alto costo de las consultas, la proporción médicos/población debe ser calculada teniendo en cuenta los estamentos sociales existentes en Caracas y su composición interna, ya que los médicos y cirujanos blancos raramente curaban a los negros, mientras que se daba el caso de cirujanos mulatos que curaban a los blancos menos ricos. Considerando los datos poblacionales de 1787, válidos en buena parte también para el 1795, podemos calcular que en Caracas había:

1. Quince profesionales médicos blancos para una población blanca de cerca de 8.000 personas, con una proporción de uno para 533 individuos blancos (sin tomar en consideración que los blancos pobres raramente podían acudir al médico titulado).

2. Ocho cirujanos mulatos para una poblacion negra, mulata, e indígena de 20.707 personas, con una proporción de uno para 2.588 individuos (sin considerar la situación precaria de los esclavos que dependían de sus dueños para la curación de las enfermedades).

Resulta evidente que sólo para el estamento más rico la situación médica puede considerarse satisfactoria. Para el resto de la población, enfermarse era un riesgo muy grande, faltándoles el dinero para curarse ${ }^{38}$. De cualquier manera, había algunas alternativas locales a los médicos titulados que permitían mejorar esta situación: la utilización de la medicina «popular» permitía resolver los problemas menos graves y, en segundo lugar, se podía recurrir a los boticarios y curanderos.

Las figuras médicas en Caracas a fines del siglo XVIII pueden dividirse en médicos europeos y criollos, cirujanos romancistas, enfermeros en los hospitales, comadronas y sangradores, etc. A éstos se añaden los curanderos. Como escribe Foción Fébres-Cordero, «...salvo algunos médicos europeos, los médicos prácticos, los cirujanos, los flebotomistas, los curanderos, eran pardos y todos ocupaban un bajo nivel social.» ${ }^{39}$.

Por lo que se refiere a los cirujanos se trataba de «prácticos» que ejercían con un permiso oficial del cabildo ${ }^{40}$. Los «barberos» sangradores no tenían licencia para ejercer y tampoco los «curanderos populares». Los cirujanos, pardos en su mayoría,

\footnotetext{
36 ARCHILA (1961), p. 226.

37 AGNC, La Colonia, Títulos de médicos, Tomo 1, folio 71.

${ }^{38}$ Cfr. Ibidem, ff. 118 y ss.

39 FÉBRES-CORDERO (1987), p. 421.

40 Cfr Perera, A. (1951), Historia de la medicina en Venezuela, Caracas, p. 46.
} 
no deben confundirse con los europeos que ejercieron en Caracas tal oficio. Éstos eran cirujanos «latinos», mientras que los locales eran considerados «romancistas»:

\footnotetext{
«La diferencia fundamental provenía del grado de capacitación, conocimientos idiomáticos y clase social. Los cirujanos latinos eran académicos, egresados de las universidades y pertenecían a la clase de los blancos. En cambio, los romancistas no eran titulados, ignoraban el idioma científico, o sea el latín, y procedían de la categoría de los "pardos". Así, pues, los primeros eran letrados, de carrera regular; los segundos, incultos y empíricos, hombres que sin estudios preparatorios, se dedicaban a la práctica, dentro y fuera de los hospitales.»41.
}

Cuando se constituya el Protomedicato los cirujanos deberán prestar un examen para conseguir la autorización de ejercer. Esta institución, de cualquier modo, dio solo diplomas de «cirujanos romancistas» 42 .

Los médicos provenían en su mayor parte de España, especialmente de las Islas Canarias. Se registra también la presencia de médicos no españoles a lo largo del siglo XVIII. No era ésta una situación nueva para Caracas: en el siglo XVII habían marcado su presencia los médicos lusitanos, en el XVIII son los franceses. Estos últimos llegaron a Caracas sobre todo en la primera parte del siglo, incurriendo en 1716 y 1736 en decretos de expulsión de los dominios españoles. Sin embargo, algunos consiguieron quedarse ${ }^{43}$. Son catorce los facultativos franceses que Foción Febres-Cordero calcula para el siglo XVIII; y su influencia sobre la formación de los médicos locales se extiende hasta el final de ese siglo ${ }^{44}$. Se debe a tres cirujanos franceses la primera trepanación craneal en Venezuela en 1736 (Blandin, Bigot y Pellerin) ${ }^{45}$. Finalmente merece ser citada la llegada a Caracas en 1771 del cirujanocomadrón francés Juan Combe, traído por el gobernador y capitán general don José Solano y Bote ${ }^{46}$.

Al lado de los catorce franceses citados encontramos en Caracas en el mismo siglo XVIII también otros médicos no españoles: dos italianos, dos alemanes, un cubano, un peruano, un dominicano y un holandés. Destaca el palermitano Francisco Fontes, que desarrolla una intensa actividad filantrópica en Caracas ${ }^{47}$. La presencia de estos médicos no españoles no siempre fue bien aceptada y, hacia el final del siglo,

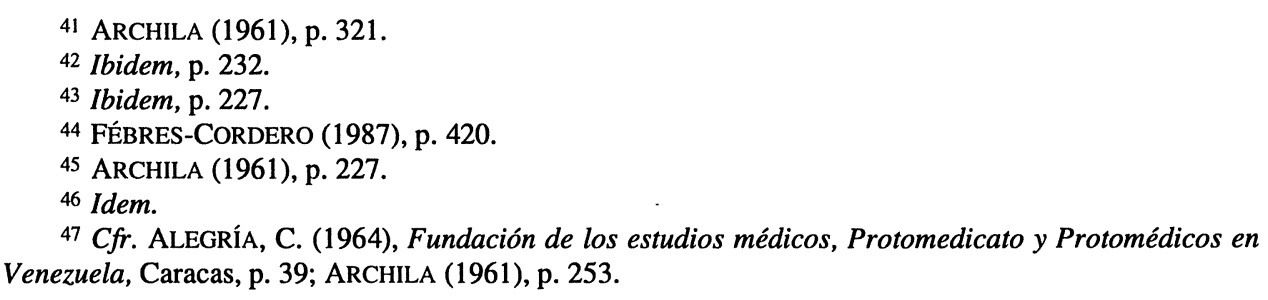


la oposición a los «forasteros» se hace explícita y patente, incluyendo a los mismos médicos originarios de la Península ${ }^{48}$.

Por otro lado, es gracias a estos médicos europeos como las nuevas ideas médicas del siglo XVIII encuentran lugar en Caracas, también a través de la importación de libros de medicina recién editados en Europa y la circulación de «cartillas» de argumento médico. Idéntica situación se producía en lo referente a la renovación de la higiene pública y organización de los hospitales.

Contrariamente a lo que suele afirmarse, en Caracas circularon muchos libros médicos en el siglo XVIII, especialmente si se tiene en cuenta el reducido número de alfabetizados. Como anota Blas Bruni Celli, desde 1730 «...grandes cargamentos de libros» llegan a Caracas ${ }^{49}$. No sólo encontramos los textos básicos de la medicina que circulaban en Europa, sino también los más polémicos sobre teoría y práctica médica.

En este contexto, es importante hacer referencia nuevamente a la obra de Feijoo. El doctor José de Urrutia, de la Compañía Guipuzcoana, tenía en su biblioteca las Cartas del fraile benedictino ${ }^{50}$. En 1742 don José de Oviedo y Baños recibe las obras publicadas de Feijoo y en 1754 don Antonio de Urrutia, de la expedición de Límites al Orinoco, trae consigo el Teatro Crítico. En 1761 se tiene noticia de la presencia de esta obra en Cumaná y en el mismo año llegan a Caracas 18 juegos de las obras de Feijoo a fray Domingo Manón, prior del convento de predicadores de Caracas ${ }^{51}$.

De Martín Martínez llega a Caracas en 1756 la Anatomía Completa del Hombre y la Medicina Scéptica ${ }^{52}$. En 1757, con el navío «San Francisco Javier», llegan a Caracas cuatro cajones de libros, entre los cuales se encuentran dos copias de la Anatomía de Martínez ${ }^{53}$.

De la otra figura fundamental para el desarrollo de la medicina en España, Félix Palacios, se conoce en Caracas la Palestra Farmacéutica-Químico-Galénica. De Guillermo Guillén encontramos la Medicina Práctica; y de Francisco Solano Luque, el Idioma de la Naturaleza.

También resulta interesante anotar que en Caracas circulaban en el siglo XVIII libros que mezclaban medicina con teorías mágicas y astrológicas. Entre éstos podemos citar libros del siglo XVII como la Verdadera Medicina, Astrología y Cirugía de Juan de Barrios (México 1607) y la Astrología y Medicina de la Astronomía de

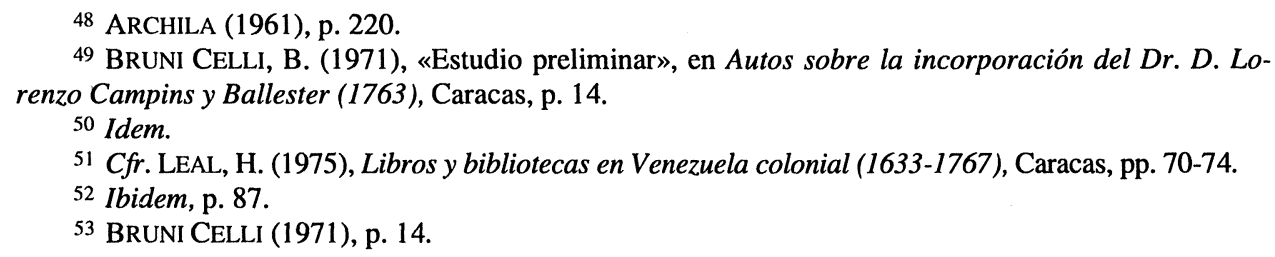


Juan de Figueroa (Lima 1660). Contra estos tipo de saber «médico» encontramos también la obra del veronés José de Gazola, El Mundo Engañado de los Falsos Médicos, traducido al español en 172954 .

Finalmente, era posible encontrar algunos «manuales», lectura de referencia para los «médicos prácticos» y los curanderos de origen no popular. Destacan, entre éstos, el Tratado de Medicina para las Diferentes Enfermedades (varias ediciones desde 1670 a 1727), de Gregorio López; el Florilegio Medicinal de todas las Enfermedades del jesuita Juan de Esteineffer (México 1712), obra escrita «para bien de los pobres y de los que tienen falta de médicos», como se lee en su portada ${ }^{55}$. También encontramos, entre las obras de este tipo, El Cirujano instruido. modo fácil y barato de curar casi todas las enfermedades externas, del francés Goulard, traducido y editado en Madrid en 177456.

Del tipo de libros que circularon en Caracas en el siglo XVIII se desprende con evidencia la participación de los médicos locales en las ideas de la Metrópoli. Por otro lado, la producción local de saber médico no es particularmente abundante, aparte lo que los curanderos producían de manera «salvaje». De hecho, no debemos olvidar que la posibilidad de estudiar medicina fue tardía en Caracas. La Real y Pontificia Universidad de Caracas fue instalada en 1725 y parece que en 1726 se llegó a activar la cátedra de medicina, tomando su posesión don Sebastián Vizena y Seixas, licenciado por la Universidad de Toledo. Sin embargo, no hay datos ni constancia que puedan demostrar que esta cátedra funcionó ${ }^{57}$. Al contrario, resulta suficientemente documentada la instalación de la cátedra de medicina en 1763 en dicha Universidad, por iniciativa del doctor Campins y Ballester, mientras que será necesario esperar una decada más, antes de que fuesen licenciados los primeros médicos titulados venezolanos.

\section{LOS CURANDEROS EN CARACAS EN EL SIGLO XVIII}

La represión de las prácticas religiosas y médico-rituales de los indígenas acompañó la conquista de América, mostrándose particularmente virulenta en México y Perú, donde existía un sistema religioso institucionalizado. Ejemplar es, en este sentido, la llamada «destrucción de las idolatrías» en Perú, en el primer siglo de la Conquista. De manera menos explícita, los mismos procesos represivos se dan también en la conquista de aquellas poblaciones indígenas cuyo sistema religioso se encon-

54 Ibidem, pp. 87, 92 y 94.

55 LEAL (1975), p. 93.

56 SilVA ÁlVAREZ (1985), pp. 39-41.

57 PERERA (1951), pp. 56-66. 
traba «difuso» en las prácticas culturales cotidianas. También entre estos pueblos, existía una figura específica que asumía funciones religiosas y médica, pero sin caracterizarse en términos sacerdotales como en el caso azteca o inca.

Los chamanes, en el fondo, eran unos curanderos que, a través del conocimiento de los recursos naturales y manejando el universo espiritual del grupo, curaban las enfermedades físicas y psicológicas (mejor sería decir «culturales»). También contra éstos la represión de los misioneros fue dura, aunque con relativa facilidad conseguían realizar sus prácticas a escondidas.

Por otro lado, fueron los mismos españoles los que recurrían a estos «médicos» indígenas en caso de necesidad. De esta manera algunas prácticas médicas autóctonas se mezclaron a otras de origen español (prácticas populares de los grupos sociales subalternos), originando múltiples sincretismos médicos, practicados normalmente en el campo y en las ciudades. Escribe George M. Foster:

\footnotetext{
«Fuese cual fuese el mecanismo, una gran proporción de la práctica médica española de la época de la conquista fue incorporada a las prácticas populares americanas. Al mismo tiempo, y por canales informales, buena parte de la medicina popular contemporánea de la metrópoli fue transferida al Nuevo Mundo. El resultado es una masa bien desarrollada y floreciente de creencias folklóricas sobre la naturaleza de la salud, las causas de las enfermedades y las técnicas curativas, compuesta de elementos americanos indígenas, de folklore español, y de medicina clásica» ${ }^{58}$.
}

La formación de sincretismos médicos no fue sólo el resultado del fenómeno normal de intercambio, implícito y automático, que se produce cuando dos culturas mantienen un contacto permanente. Hay también un origen más específico: los curanderos indígenas manejaban con mayor conocimiento las enfermedades endémicas y. su curación y, por esto, sus métodos fueron asumidos por los españoles pobres y, en segundo término, también por los estamentos sociales dominantes ${ }^{59}$. El proceso era facilitado por la falta de médicos españoles titulados, hasta por lo menos la mitad del siglo XVIII60.

No cabe duda de que con los soldados de la conquista y con los emigrantes que los siguieron, llegaron de España también curanderos populares. En este sentido, por ejemplo, el «Salutador» español tiene en época colonial sus correspondientes en

\footnotetext{
58 FOSTER, G. M. (1980), «Relaciones entre la medicina popular española y latinoamericana», en $L a$ antropología médica en España. Compiladores: Michael Horney y Jesús M. de Miguel. Barcelona, p. 127.

59 Cfr. DomíngueZ, R. (1925), «El Dr. Lorenzo Campins y Ballester, fundador de los estudios médicos en Venezuela», Anales de la Universidad Central de Venezuela, XVII, Caracas, pp. 391-92.

${ }^{60}$ No debemos olvidar el interés por la «materia médica americana» demostrado en los tres siglos de la Colonia y, particularmente, en la segunda mitad del siglo XVIII (ver, por ejemplo, las actividades del «Jardín Botánico» de Madrid).
} 
America, como en el caso del «Perspicaz» chileno ${ }^{61}$. De la misma manera, las prácticas populares de «rezar sobre una enfermedad», ampliamente presente en la Península, se las traslada al Nuevo Mundo. El «rezador» presente entre pueblos indígenas de lengua caribe del norte de Brasil tiene en parte este origen.

Muchas veces, estos curanderos populares fueron reprimidos como hechiceros. En Lima, entre 1625 y 1666, fueron procesados un centenar de «hechiceros», de los cuales más de la mitad fueron condenados por el Tribunal de la Inquisición. Siempre en el caso peruano, en el siglo XVIII, fueron sobre todo varones los acusados de hechicería, entre los cuales encontramos algunos frailes condenados por «pacto» con el diablo. En 1736 un fraile dominicano fue condenado por ser «doctor en malvada brujería» ${ }^{2}$. De cualquier manera, en el siglo XVIII no encontramos un gran número de casos de «hechicería» reprimida por los tribunales.

En la provincia de Venezuela fue muy sonado el caso de Juan Alonso de la Cruz, «indio natural de la jurisdicción de Caracas», procesado por «curar supersticiosamente». El hecho, acontecido en 1761 en Valencia, nos permite dar cuenta del sincretismo médico existente en Venezuela. El curandero denunciado, que había aprendido la profesión acompañando a un médico, había curado una mujer con «yerbas» y «oraciones» cristianas haciéndole «arrojar una culebra y porción de gusanos y un sapo que tenía en el vientre»63. Esta «enfermedad» había sido provocada por un maleficio que la comadre de la enferma, mulata, le había hecho.

Tenemos así un curandero indígena que ejerce su profesión en Caracas y es conocido también en la Provincia, y que diagnostica y cura utilizando un modelo sincrético donde están presentes elementos españoles e indígenas. De estos curanderos estaban llenas todas las ciudades americanas, lo que José Hipólito Unanue describe, para la Lima de 1792, como «...una peste de curanderos y charlatanes, que iba devorando por todas partes la vida y la substancia del vulgo.» ${ }^{64}$.

Al lado de estos curanderos populares, definidos como «hechiceros», encontramos otros que no son acusados de curar «supersticiosamente» pero sí de ser «charlatanes» y de curar sin autorización. Así que es preciso, ante todo, definir semánticamente estas figuras ya que el término «curandero» es utilizado para indicar al mismo tiempo los que curan «supersticiosamente» y los «charlatanes».

Por lo que se refiere a los «que curan supersticiosamente», el término «curandero» es asociado casi siempre a los de «hechicero» y «brujo/a». Para este último, el Dic-

\footnotetext{
${ }^{61}$ Cfr. FOSTER (1980), p. 141.

${ }^{62}$ Cfr. TORIBIO MEDINA, J. (1887), Historia del Tribunal del Santo Oficio de la Inquisición de Lima (1769-1820), II, Santiago.

${ }^{63}$ Los datos sobre este caso se encuentran en AGNC, Diversos, tomo IX, ff. 367-77 vto.

${ }^{64}$ En CLÉMENT, J. P. (1987), «Decadencia y restauración de la medicina peruana a fines del siglo XVIII». Asclepio, vol. XXXIX (2), Madrid, p. 218.
} 


\section{EMANUELE AMODIO}

cionario de la lengua castellana de 1726 dice que se trata del «hombre malvado, que obra con pacto con el demonio como las brujas» ${ }^{65}$. En la edición de 1770 el Diccionario caracteriza tal hombre como «supersticioso», mientras que para la definición de «Bruxa», añade que tal mujer tiene pacto con el demonio «según la opinión vulgar». Resulta evidente que la diferencia entre las dos ediciones del Diccionario, manifiesta la distancia tomada por los lingüistas ilustrados de la pretendida «realidad» del evento mágico.

En el caso de los documentos analizados para los curanderos en Caracas a finales del siglo XVIII, el término curandero es asociado también a los de «intruso» y «curioso». El Diccionario de 1726 define la «intrusión» como «...entrada en alguna parte, oficio u dignidad, sin derecho alguno» ${ }^{66}$, y Corominas reporta su uso por parte de Feijoo en el campo médico, lo que debía ser ya tradicional desde el siglo anterior $^{67}$. El término «curioso» deriva del curiosum latino: «cuidadoso, minucioso, ávido de saber», refiere Corominas. Su uso en el campo médico no debía ser muy antiguo si consideramos que el Diccionario de 1726 no lo incluye. Finalmente, este incluye una definición de «curandero»: «El que sin ser médico aprobado, anda aplicando medicinas que supone ser específicas para el remedio de algunas enfermedades.»68Definición clara que parece excluir los significados de «hechicero» y semejantes.

Sin embargo la definición resulta bien amplia si consideramos que en la explicación sucesiva del término se citan «los curanderos intrusos» de la obra Luz de Verdad Cathólica de Parra, al lado de «los Machis, que son sus curanderos o médicos», referido sin duda a los chamanes araucanos chilenos, cuya descripción los extensores del Diccionario toman de la Historia del Reino de Chile. del padre Alonso de Ova$1 e^{69}$. Resulta así claro que el término «curandero», en el uso del siglo XVIII, se coloca en la frontera entre dos campos semánticos diferentes, aunque contiguos, de acuerdo con el siguiente esquema:

\footnotetext{
65 «Diccionario de Autoridades» (1726), p. 652.

66 «Diccionario de Autoridades» (1726), p. 299.

${ }^{67}$ COROMINAS, P. A. (1986), Diccionario crítico etimológico castellano e hispánico, Madrid.

68 «Diccionario de Autoridades» (1726), p. 206.

69 «Diccionario de Autoridades» (1726), p. 706.
} 


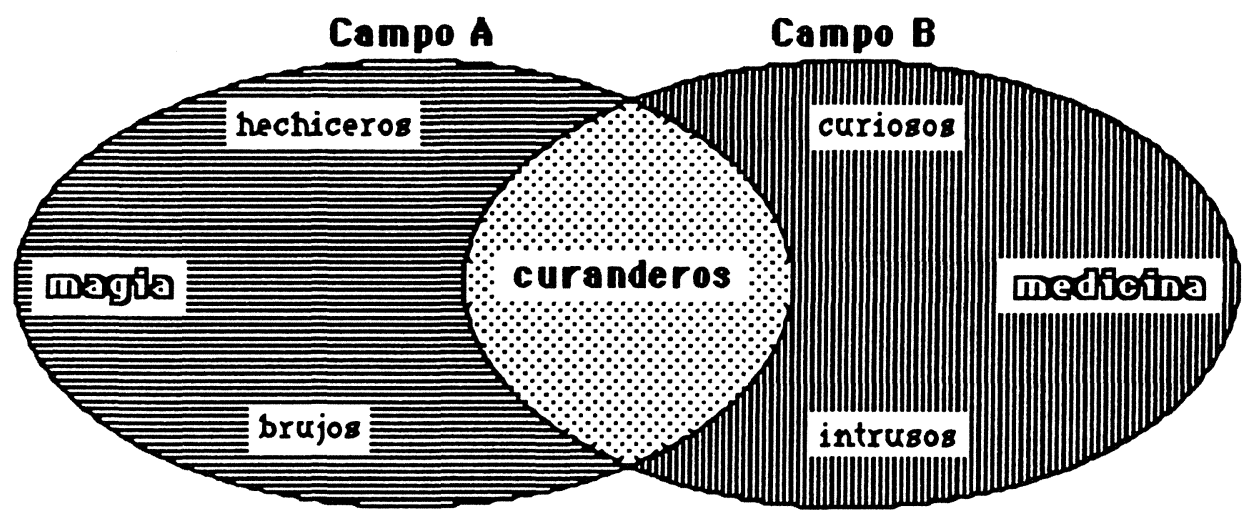

En el caso de los curanderos de Caracas parece evidente la utilizacion del término en el contexto del campo semántico B del esquema, es decir de la «medicina». Aquí, estos «curanderos» tuvieron amplias posibilidades de ejercer en consideracion al reducido número de profesionales dispuestos a atender a la población de los estamentos más bajos. De hecho, la mayoría de los curanderos criollos eran pardos. El Cabildo intentó controlar el «intrusismo predominante», como lo llama Ricardo Archila ${ }^{70}$, consiguiendo en parte frenar el fenómeno con la entrega de permisos para ejercer la cirugía. Sin embargo, los curanderos no se limitaban a ejercer en este solo ámbito.

Desde el comienzo del siglo los médicos titulados habían denunciado esta actividad «ilícita». En 1702, el doctor Fernando Gómez de Munar denuncia al capitán general la situación y consigue que se emita una Ordenanza para obligar a los curanderos a presentar sus títulos y, en caso de falta de éstos, los obligaba a no ejercer bajo la amenaza de una multa de 200 pesos. Sin embargo, la situación médica local y la aceptación popular no permitieron la actuación de la medida ${ }^{71}$.

En 1741 el mismo problema es presentado en Madrid por el canario doctor Carlos Alfonso y Barrios. Este médico, residente en Caracas desde 1735, propone crear un Protomedicato para controlar los «curanderos idiotas, mestizos, mulatos y tal vez negros bosales... que con gran aceptación pública se dedican a curar originando graves desgracias y perjuicios» ${ }^{72}$. La solicitud es rechazada, a pesar de ser apoyada por la Real y Pontificia Universidad de Caracas.

70 ARCHILA, R. (1956), Historia de la sanidad en Venezuela, I, Caracas, p. 21.

71 PERERA (1951), p. 44

72 Alegría (1964), p. 58. 
No tenemos muchos datos biográficos sobre estos curanderos. Los documentos de la época registran, por lo menos hasta la instalación del Protomedicato en 1777, sólo aquéllos que adquirieron fama particular. En las primeras décadas del siglo se hicieron famosos dos curanderos apodados «el saboyano».y el «dinamarqués» que Vargas un siglo después llamaba «medicastros». En 1762 era conocido otro curandero lusitano, don Antonio Joaquín Troetz, llamado el «portugués», junto con un cirujano italiano, Giuseppe Priscini, ambos sin título. En la misma época, encontramos los criollos Diego José de los Reyes, que fray Antonio Caulin cita como «médico yerbatero»; José Luciano de la Santa; Juan José Rangel y Juan de Goitia, ambos «curiosos algebristas» ${ }^{73}$. En 1778, cuando ya estaba activo el Protomedicato, resultan llamados oficialmente a examen en Caracas catorce curanderos. De éstos, algunos ejercían también en campos afines al del «curanderismo», por ejemplo como cirujanos de la tropa ${ }^{74}$.

Estos curanderos no deben confundirse con los de origen popular salvo en casos específicos. Se trata de «médicos prácticos», alfabetizados, de los cuales algunos tenían título de médico conseguido fuera de España y no reconocido en Caracas. Otros declaraban poseer títulos, pero no eran capaces de exhibirlos.

La formación de estos curanderos, sobre todo los criollos, era de tipo práctico, conseguida, en general, trabajando de ayudante de un médico o de otro curandero. Escribe Ambrosio Perera:

\footnotetext{
«Algunos de dichos cirujanos habían adquirido sus conocimientos de labios de viejos curiosos, con credenciales o no de cirujanos, como también de parte de algunos médicos peninsulares. No puede dejar de verse en esto una especie de escuela médica en la que reinaba la libertad de enseñanza, si se toma en cuenta que los discípulos de tales médicos o curanderos, tenían la posibilidad de obtener del cabildo el título de cirujano, que si no legalmente sí de hecho, y con complacencia oficial, los acreditaba para ejercer también la medicina, con la misma categoría y extensión que los señores universitarios.»75.
}

Además, eran ampliamente utilizados «folletos» $\mathrm{y}$ «cartillas» sobre medicina práctica para diagnosticar enfermedades y aplicar curaciones. Cundía entre el pueblo la afirmación de que los curanderos curaban mejor que los médicos titulados. Ambrosio Perera cita el caso del juicio del médico titulado Francisco Guerra Martínez contra el barbe-

\footnotetext{
73 ARCHILA (1961), p. 297. Se llamaba algebrista quien concertaba los huesos dislocados (cfr. DOMÍNGUEZ [1925], p. 394).

74 ARCHILA (1961), p. 298.

75 PERERA (1951), p. 47.
} 
ro español Manuel Espinoza, de quien los testigos afirmaban que curaba «...con acierto mayor y con más crédito y acertada caridad que Guerra Martínez» ${ }^{76}$.

Aun considerando un poco exagerada tal afirmación, en el fondo debía haber algo de verdad. Los médicos graduados continuaban, en efecto, con sus sangrías y la aplicación automática de los «aforismos» de Hipócrates, mientras que los curanderos, por su misma condición social y cultural de «frontera», estaban más abiertos a acoger en sus curaciones prácticas de origen indígena, o novedades médicas llegadas de Europa. El caso de la inoculación contra la viruela lo demuestra ampliamente.

Como se recordará, citamos la introducción en Caracas de la «inoculación» contra la viruela por el doctor Juan Perdomo en 1765, al precio de diez pesos por cada «inoculación». La simplicidad del método permitió una rápida aceptación en Caracas, lo que en parte se debió a su utilización temprana por parte de los curanderos. Como escribía en 1804 el Licenciado Salias en sus Memorias (1804), «...los curanderos y los curiosos en competencia con los médicos ponían en práctica la inoculación de la viruela desde fines del siglo último» ${ }^{77}$.

Finalmente, merece ser subrayado que al lado de los curanderos de sexo masculino, encontramos también algunas mujeres que ejercían la profesión. Tenemos la sospecha de que es más en el grupo de «curanderos populares» (campo semántico A del esquema anterior) en el que se encontraban estas mujeres. El reducido número de mujeres entre los curanderos cultos tal vez se explica por la diferente situación social vivida por los dos sexos en la época. De hecho, es evidente que había más alfabetizados entre los hombres que entre las mujeres ${ }^{78}$.

En la segunda mitad del siglo XVIII encontramos referencias a la existencia de, por lo menos, cuatro curanderas afamadas: Juana Prudencia de Maldonado, comadrona y curandera; Josefa Santana Hermosa, boticaria; María Gregoria Ramos Casanueva, cuyas actividades fueron prohibidas por el Protomédico Campins; y Agustina Rangel, famosa por haber curado una hernia al religioso capuchino fray José de Soto ${ }^{79}$.

\section{CURANDEROS Y PROTOMEDICATO EN CARACAS A FINALES DEL SIGLO XVIII}

El médico mallorquín Lorenzo Campins y Ballester, graduado médico en Gandía en 1755, llegó a Caracas en 1762. El mismo año presentó su petición de ejercer en

\footnotetext{
76 PERERA (1951), p. 43.

77 En RIVERO, R. (1931), Historia médica de Venezuela hasta 1900, Caracas, p. 65. Tal vez merece ser recordado que el auge de la vacuna contra la viruela se da sobre todo a partir de 1803, año de llegada de la «Expedición Filantrópica de la Vacuna» (cfr. AGI, Indiferente general, 1558 A).

${ }^{78} \mathrm{La}$ identificación mujer/bruja sirve, de cierta manera, para facilitar la contraposición magia/medicina, donde el segundo término (medicina) es asociado a los hombres.

${ }^{79}$ Cfr. ARCHILA (1961), p. 310. 
Caracas al Cabildo de la ciudad, lo que obtuvo en marzo. En 1763 consigue incorporarse a la Universidad como Catedrático de medicina, inaugurando el 10 de octubre de 1763 la enseñanza de la medicina en Caracas. Regirá dicha cátedra durante 20 años seguidos, habiendo sido confirmado «cathedrático propietario de medicina» en 1777. La obra de Campins y Ballester, es importante para la historia de la medicina en Venezuela, tanto por haber impulsado los estudios médicos en Caracas, como por la promoción de servicios médicos en la ciudad. En los años setenta del siglo XVIII fue a la vez profesor de medicina, médico de hospital y del colegio seminario. A estos cargos se sumó en 1777 el de Protomédico, que conllevaba también los de Alcalde de leprosos, Visitador, Examinador y Juez mayor de todos los médicos, cirujanos, algebristas, oculistas y destiladores y, sobre todo, Examinador de los curanderos. Campins enferma de «melancolía involutiva» en 1784 y muere en febrero de $1785^{80}$.

De la formación intelectual y de las ideas médicas del doctor Campins poco sabemos, aparte lo expresado en las peticiones a la Corona relativas a la cátedra de medicina y al Protomedicato. Al parecer no escribió obras de medicina, aparte de algunos cuadernos manuscritos que utilizaba en sus clases en la Universidad y que contenían selecciones de obras clásicas de argumento médico ${ }^{81}$. Entre éstas debían primar los «aforismos» de Hipócrates, de los cuales Campins era un experto, como había demostrado en el examen de incorporación a la Universidad de Caracas ${ }^{82}$. El método de enseñanza de Campins fue ampliamente criticado por su sucesor el doctor Felipe Tamariz que, después de haber utilizado por un tiempo los mismos cuadernos, los sustituyó con la Medicina Práctica de Guillermo Cullen y la Cirugía de Serenas y Medina ${ }^{83}$. Ricardo Archila anota que los cursos de Campins incluían «fisiología, patología, higiene, terapéutica y nociones sobre la orina y el pulso»84; y Arístides Rojas refiere que «...la ciencia del doctor Campins se reducía a nociones de Anatomía y Fisiología, a la Patología de aquella época y al conocimiento de la terapéutica y materia médica que desde remotos tiempos se enseñaban en las aulas de España» ${ }^{85}$.

Estos datos nos llevan a considerar al doctor Campins como un exponente de la medicina oficial española, no particularmente abierto a las innovaciones y transmisor de una enseñanza ya clásica en las últimas décadas del siglo XVIII. Sin embargo, Campins participa de los procesos ilustrados de reforma, sobre todo en el nuevo modo de considerar la organización de las instituciones. Estas conclusiones son confirmadas por su actividad social que, sin desestimar su interés por los problemas de

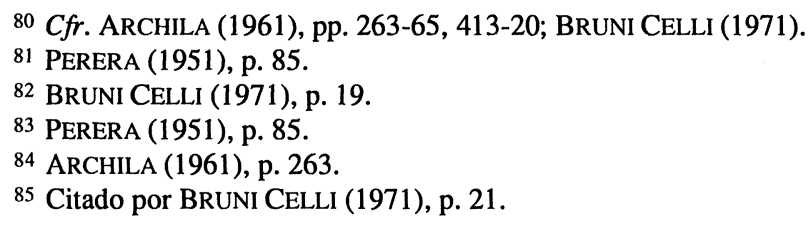


salud de la ciudad, estuvo dedicada a la lucha contra los curanderos, abogando para un control oficial de la profesión médica.

En 1775 el doctor Campins propone al Rey instituir el Protomedicato en Caracas, avanzando su candidatura para tal cargo. Función principal del Tribunal del Protomedicato era fiscalizar a los que ejercían la medicina, con particular atención a los no graduados en la Universidad. El control, así, incluye a barberos sangradores, boticarios, cirujanos y curanderos. Teóricamente, el Protomedicato debía examinar a dichos «profesionales» y dar o no licencia para el ejercicio médico. La Recopilación de Leyes de los Reynos de las Indias (1681), en su Título seis del libro V, titulado De los Protomédicos, Médicos, Cirujanos, y Boticarios, daba indicaciones precisas sobre tal institución. Ésta debía informar sobre todos los «profesionales» de la salud existentes en el lugar (españoles e indios); informar sobre yerbas y semillas medicinales; examinar y dar licencias. Sobre esta última ordenanza, la Ley IV era muy explícita: «Mandamos que no se consienta en las Indias a ningún género de personas curas de medicina, ni cirugía, si no tuvieran grados, y licencia del Protomédico.»

Este conjunto de funciones se habrá definido en España en el curso de varios siglos, desde la creación del primer Protomedicato por Alfonso III de Aragón en 1285. La institución adquiere su carácter definitivo después de la llegada española a America, y particularmente con Felipe IV en el siglo XVII. En México (1517) y Lima (1536) encontramos los primeros Protomédicos de América. En 1570 fue nombrado un Protomédico General de todas las Indias (los otros no tenían el carácter de «general»), el doctor Francisco Hernández, con la función de recolectar datos y muestras de yerbas medicinales en las Indias (encomienda que cumplió muy bien, después de vivir siete años en México) ${ }^{86}$. En el siglo XVII fueron fundados los Protomedicatos de Bogotá, Cartagena, La Habana, Guatemala y Quito. En el siglo XVIII, la institución recibe un nuevo impulso en España con la subdivisión en tres Audiencias (hasta ese momento había sólo un Protomedicato central), mientras en América se crea el de Panamá (1725) y Chile (1756) ${ }^{87}$.

En Caracas el primer intento de instituir el Protomedicato se da en 1680. El Gobernador de la Provincia nombró protomédico al doctor Bernardo Marín de Guzmán; sin embargo, el Rey no ratificó el nombramiento por no caer tal prerrogativa entre las de los gobernadores. En 1701 el doctor Ruiz-Carvallo pidió para sí tal título a la Real Audiencia, la cual respondió negativamente. Otra tentativa se dio en 1740 por el doctor Carlos Alfonso Barrios y tampoco obtuvo éxito ${ }^{88}$. Llegamos así a la propuesta de Campins en 1775.

\footnotetext{
${ }^{86}$ SCHAFFER, E. (1964), «Los Protomedicatos en Indias». Revista de estudios americanos, III, Sevilla, p. 4.

87 BRUNI CELLI (1971), p. 23.

88 FÉBRES-CORDERO (1987), pp. 425-26.
}

Asclepio-Vol. XLIX-1-1997 
El 19 de marzo de ese año el doctor Campins envió una carta al Cabildo de Caracas comunicando su intención de pedir al Rey la creación del Protomedicato. Campins reconoce que la facilidad con la cual el Cabildo autoriza el ejercicio de cirujanos, boticarios, etc., es debida a la «pura necesidad». Sin embargo, anota que la falta de entusiasmo en estudiar medicina por parte de los criollos debe considerarse un producto de esa misma liberalidad: hay demasiados «curanderos»y, por esto, pocos quieren dedicarse a la profesión.

«...Son muy pocos los que se han aplicado a una profesión tan apetecible, cuando de ella
ay tan corto numero en estos parages, y examinando los motivos que puedan ocasionar se-
mejante tibieza en los ánimos de los moradores que cursan las Letras, he averiguado por
única y principal causa la toleración de crecido numero de curanderos o Curiosos que siendo
la ruina de la salud humana tan recomendable, hacen perder el fervor a los que con conoci-
miento advierten la ninguna recompensa que pueden esperar de sus dilatadas tareas mirando
en manos de los Idiotas una profesión tan particular...»89.

El 12 de julio del mismo año el doctor Campins envió su petición a España, ampliando su análisis de la situación médica de Caracas ${ }^{90}$. Es importante resaltar que para Campins la institución del Protomedicato está interrelacionada con el problema de los estudios médicos en la Universidad. De hecho, después de más de diez años de impartir clases de medicina pocos habían sido los estudiantes y los frutos de tal actividad. En búsqueda de una explicación, Campins llega a la conclusión de que los motivos deben ser buscados en la proliferación de curanderos. Según su escrito al Rey de 12 de julio de 1775, a su llegada había constatado la ausencia de médicos, provocada por la proliferación de curiosos y curanderos, tolerados por el Cabildo por la necesidad existente en la ciudad. Tras obtener la cátedra de medicina de la Universidad, con la finalidad de «...exterminar con el gran número de profesores la multitud de curanderos, o curiosos», y después de nueve años de dar clase, «...se ha visto como al principio»: pocos alumnos y muchos curanderos ${ }^{91}$.

Estamos en presencia de uno de los paradigmas de la Ilustración, el más «ingenuo» tal vez. Es decir, frente a un problema, identificado como fruto de la ignorancia, la

89 «Carta de Campins al Cabildo de Caracas» (19 de Marzo de 1775), AGI, Caracas, 261.

$90 \mathrm{Al}$ mismo tiempo que la propuesta al Rey para el Protomedicato, Campins envía otra comunicación donde pide la propiedad de la cátedra de medicina. C fr. «Pedido de la propiedad de la Cátedra de Medicina del Colegio de Santa Rosa de Lima de parte de Campins y Ballester» (12 de julio de 1775), AGI, Caracas, 241.

91 «Carta de Campins al Cabildo de Caracas» (19 de marzo de 1775), AGI, Caracas, 261. Sobre las relaciones entre enseñanza de la medicina y pensamiento ilustrado, cfr. QUEVEDO, E. (1985), «La ilustración y la enseñanza de la medicina en la Nueva Granada», en PESET, J. L. (ed), La ciencia moderna y el Nuevo Mundo, Madrid. 


\section{CURANDEROS Y MÉDICOS ILUSTRADOS}

simple presencia o anuncio de las «luces» del verdadero conocimiento sería suficiente para resolverlo. Después de diez años de proferir, desde la cátedra de medicina, la que pensaba que era «verdad médica» frente a la «falsedad» de los prácticos curanderos, Campins declara fracasado su intento, proponiendo soluciones más drasticas: «...siempre que los curanderos, o curiosos queden tolerados como hasta aquí, muy pocos, o ningunos son los que se dedican a cursar la profesión, principalmente a ser como son los dichos curanderos de calidad inferior como mulatos o negros, en cuyas manos puesta la medicina, la han hecho decaer de su esplendor, y circunstancia.»92.

De esta manera, Campins muda sensiblemente su análisis de la realidad médica de Caracas, proponiendo una solución diferente: se debe instituir un control más rígido y reprimir si es necesario. Para justificar esta opción, aparte del análisis de su fracaso como profesor de medicina, Campins propone una explicación socio-económica a la falta de estudiantes criollos: a causa del gran número de curanderos «mulatos» y «negros», la medicina en Caracas es identificada como profesión despreciable, perteneciente a los estamentos más bajos de la sociedad. Los criollos desdeñan dedicarse a esa profesión para no ser confundidos con tales «negros», siendo temerosos de «...malograr el fruto de sus tareas» 93 .

La introducción de las figuras de «mulatos» y «negros» en la cuestión permite comprobar la «ambigüedad» semántica del término «curandero». Campins continúa utilizando este término como sinónimo de «curioso», dándolo siempre como explicativo del otro (a través de la partícula «ó»). Nunca utiliza el término «hechicero» pero, deslizándose más o menos corrientemente hacia este ámbito, lo insinúa con la referencia a los «negros». Es decir, Campins coloca la contraposición entre «negros» y «criollos» como explicativa del rechazo, dentro del ámbito mayor, para el médico, de la oposición entre una medicina «científica» (o «verdadera») y una «nocientífica», ligada a las creencias populares. De esta manera, a través del silencio sobre los curanderos criollos no negros existentes en Caracas, Campins intenta asegurar el éxito de su propuesta.

En su petición al Rey justifica su proposición en términos extremos: o se instituye el Protomedicato en Caracas o la medicina quedará en manos de «negros» y «mulatos». En realidad, el problema sólo en parte incluye a los «curanderos negros». Más bien éste se desarrollaba entre criollos, como contraposición entre figuras médicas oficiales y tituladas y figuras no reconocidas por las instituciones, pero ampliamente presentes en la realidad caraqueña.

En Madrid, el Consejo de Indias analiza la propuesta de Campins de instituir el Protomedicato en Caracas y el 29 de diciembre de 1775 el fiscal encargado presenta

\footnotetext{
92 Idem.
}

93 Idem. 
su relación ${ }^{94}$. Una vez constatada que la propuesta no «tiene extrañeza» por ser prevista en las Leyes de Indias, el Fiscal recomienda prudencia y propone pedir informaciones suplementarias en Caracas sobre el comportamiento y motivaciones del postulante y la existencia en la ciudad de otros médicos graduados. Además, advirtiendo que la petición de Campins carece «de perfecta instrucción», recomienda que se pidan a Caracas «informes reservados» al gobernador, al Ayuntamiento, al rector y al Claustro de la Universidad. El pedido de «informes reservados» es enviado a Caracas el 15 de marzo de 1776 y en agosto del mismo año las respuestas son despachadas hacia Madrid. Veamos particularmente cada respuesta.

El 29 de junio de 1776 se realiza en Caracas un Cabildo extraordinario donde se analiza el asunto y se decide reunir informaciones suplementarias sobre el caso ${ }^{95}$. El Cabildo vuelve a reunirse el 5 de julio para discutir nuevamente el tema y se encarga un informe a don Fernando Blanco ${ }^{96}$. Finalmente, en la reunión del 23 de agosto se lee el informe a los participantes de la reunión, el cual es aprobado ${ }^{97}$. La respuesta del Cabildo reafirma en parte el análisis de Campins, reconociendo la utilidad del Protomedicato. Sin embargo, frente a la falta de médicos graduados se propone permitir la actividad de los curanderos: «... pero que entretanto se provea de profesores de medicina, de que tanto escasea, se permita a los curiosos, que han manifestado acierto en las curaciones, este exercicio, acordándose por el Cabildo, y el Protomédico que V.M. se digne a nombrar, los que pueden continuar, y á los que debe prohibirse.»98.

Resulta evidente que el Cabildo quiere defender su anterior actitud hacia los curanderos, a algunos de los cuales había dado permiso de ejercer. Por otro lado, tal vez en consideración de un conocimiento más profundo de la realidad local, piden que se mantengan en actividad los curanderos, disminuyendo así la contundencia de la propuesta de Campins y, por ende, el poder de éste una vez conseguido el cargo. Por esto, se propone que el Cabildo participe en los futuros exámenes para decidir quién será autorizado a ejercer la medicina.

La respuesta del gobernador y capitán general de la provincia de Venezuela, Don Josef Carlos de Aguero, es bien diferente. Fundamentalmente, su parecer es negativo, proponiendo denegar el pedido de Campins, aunque reconoce que «...ha manifestado conducta juiciosa y buena índole.» Sin embargo, no le reconoce un buen

\footnotetext{
94 «Relación del Fiscal del Consejo de Indias sobre el pedido de Campins» (29 de diciembre de 1775), AGI, Caracas, p. 241.

95 AAC, Cabildos de Caracas, tomo LII, 1775-1777, f. 57 vto.

96 Ibidem, f. 58 vto.-59 rto.

97 Ibidem, f. 69 rto.

98 «El Cabildo de la Ciudad responde al pedido de informaciones sobre el Dr. Campins» (23 de agosto de 1776), AGI, Aud. Caracas, 241.
} 
conocimiento de la realidad local, ni le atribuye mucho saber médico, salvo en el campo teórico. Lo que más interesa aquí de la respuesta del gobernador son las motivaciones que adelanta para su respuesta negativa y el análisis del saber de los curanderos. Citamos parte del texto:

«...Este sugeto estudió la Medicina en la Universidad de Valencia, es algo sobresaliente en la Theórica, pero en la práctica se le han reparado algunos desaciertos originados de el poco conocimiento del clima, y enfermedades del País, las cuales naciendo por lo común de unas mismas causas, se curan con unos propios medicamentos, y simples, cuya virtud enseñó la necesidad, y la aplicación á algunos de estos Naturales que los ministran con admirable oportunidad como lo testifican los enfermos que he visto entregarse ciegamente a su metodo de curación; y pareciéndome esta costumbre contraria á lo que disponen las Leyes, les tengo mandado que en las enfermedades agudas en que sea preciso aplicar remedios muy activos, y que pueden producir graves consecuencias, tomen consejo, y nada executen sin el dictamen de los verdaderos Profesores de Medicina, y vaxo de esta regla, han asistido á los enfermos á satisfacción del publico, que les contribuye por este trabajo, un Salario muy corto; y si se estableciera en esta capital Protomedicato, quedaría estinguida, y perseguida esta especie de Curanderos prácticos, y la más parte del Pueblo no podría costear el salario de un Medico de Profesión, que por cada visita lleva regularmente cuatro reales de plata. Por estos motivos, y por conocer de propia experiencia el carácter, y genio activo, y penetrante de estos curiosos, y que en la mas parte de los Reynos de América, no se puede hacer observar en todo su rigor y precisión la reglas generales que muchas vezes ha sido preciso restringir y modificar según su constitución: No tengo por conveniente al Servicio de V. M. ni al bien de estos vecinos, que tenga efecto la pretensión del Dr. Campins, sugiero que por otra parte ha manifestado Conducta juiciosa, y buena índole.»99.

El parecer del gobernador contiene tres núcleos muy importantes: 1) existen enfermedades locales que necesitan curaciones apropiadas que los «naturales» conocen mejor que los médicos venidos de afuera; 2) la pobreza del pueblo no permite pagar a los médicos y si se extinguen los curanderos su salud empeorará; 3) las características particulares de América no permiten aplicar en todo su rigor las leyes emanadas desde España.

Resulta evidente la importancia del análisis de Aguero, fruto de su amplia experiencia americana a la cual hace referencia para justificar su negativa. En toda América hay curanderos, dice Aguero, y éstos tienen buenos conocimientos de medicina y yerbas curativas a través de los cuales consiguen curar. Además, cuando necesitan de ayuda recurren al saber de los médicos titulados.

Completamente a favor de la propuesta de Campins están el Claustro universitario y el mismo Rector. En julio de 1776 se reúne el Claustro decidiendo apoyar la

\footnotetext{
99 «El Gobernador de Caracas, Joseph Carlos Aguero informa sobre la conducta del Dr. Campins y expresa su parecer sobre la creación del Protomedicato» (22 de agosto de 1776), AGI, Caracas, 241.
} 
propuesta, ahondando más en la responsabilidad de los curanderos mulatos. Esta respuesta parece una defensa tenaz del «cuerpo académico», depositario del saber oficial, contra unas figuras no institucionales, portadoras de un «saber salvaje», sin control del Estado. Se lee en el «Informe»:

\footnotetext{
«...Hemos resuelto uniformemente en Claustro pleno de primero de julio de este mismo año exponer con la mas reverente devida atención á V.M. ser muy útil, y del publico bien la enunciada pretensión del Dr Dn Lorenzo Campins en orden al Protomedicato: pues desde luego por este solo modo se acertaría extirpar de raíz la multitud de mulatos curanderos, que bien lejos de los verdaderos fundamentales principios del arte Médico, con una, ú otra mal entendida suma theórica, de aquellas, que corren en estilo vulgar, se arropan á practicar curaciones en todo el vecindario, con manifiesto daño de la salud humana del mismo» ${ }^{100}$.
}

Se comprueba así, lo que ya habíamos adelantado sobre el saber de los curanderos: circulaban unos textos que servían para aprender a curar, fuera de la institución universitaria. Por otro lado, la respuesta hace referencia a la presencia en Caracas de «profesores hábiles, que vienen de Europa» que, a su vez, según los profesores universitarios del Claustro, también preocupados por la presencia de «mulatos curanderos» deciden irse a otros lugares. La causa sería que «...el vulgo ciego, que siempre es mayor en número, clama por los referidos mulatos».

Por su parte, el Rector Don Domingo de Berroterán, aun habiendo participado en la reunión del Claustro donde se elaboró la respuesta a Madrid, decide enviar una propia carta donde retoma los mismos temas, atribuyendo a Campins éxito en las curaciones y expresando su acuerdo con la necesidad de «extirpar... tanta gente idiota que se halla ocupada en curaciones». El Rector hace referencia también al saber de estos curanderos: «...pues apenas un barbero, sastre, ó otro oficial mecánico se instruye de una suma, ó recetario, que comienza públicamente á hacer curaciones, en que se experimentan mil extragos» ${ }^{101}$

Las reacciones del pedido de Campins de instituir el Protomedicato pueden así resumirse:

Gobernador

Contrario

\section{Cabildo}

De acuerdo, pero

manteniendo

los curanderos

\section{Claustro}

De Acuerdo

\section{Rector}

De acuerdo

\footnotetext{
100 «Respuesta del Claustro de la Universidad de Caracas al pedido de informaciones sobre el Dr. Campins» (21 de agosto de 1776), AGI, Caracas, 241.

101 «Respuesta del Rector Don Domingo de Barroterán al pedido de informaciones sobre el Dr. Campins» (24 de agosto de 1776), AGI, Caracas, 241.
} 
Tenemos la impresion que esta parcial división de campo sea expresión de otra contraposición entre los «intelectuales» locales, abocados a mantener sus privilegios de casta, y los «políticos», más atentos a la realidad e interesados en mantener buenas relaciones con la población. En este sentido, en Caracas, la institucionalización del saber y su control por el Estado, expresión del «Despotismo Ilustrado», parece ser sólo parcialmente aceptada por los políticos, al contrario de lo que pasaba en la Metrópoli. Habría que ahondar más en el tema para convalidar esta conclusion pero, de cualquier manera, los eventos políticos caraqueños de las décadas sucesivas a estos años parecen confirmar nuestra idea.

El 17 de enero de 1777 el Fiscal del Consejo de Indias, habiendo reunido todos los informes, presenta la relación final sobre el caso. Su propuesta puede considerarse fruto de una mediación entre las varias hipótesis formuladas: se propone la creación del Protomedicato en Caracas, pero permitiendo a los curanderos más hábiles ejercer, después de superado un examen sobre sus conocimientos médicos. La propuesta del Fiscal reproduce la del Cabildo, teniendo muy en cuenta el parecer del Gobernador. Además, el Fiscal expresa su parecer sobre los curanderos, demostrando estar bien enterado de la materia. Veamos sus razones:

\begin{abstract}
«En todos tiempos y en todos los Pueblos aparecen Personas indoctas, y muchas veces rústicas y bárbaras que preconizando una habilidad heredada, ó un conocimiento práctico, y experimental de algunas Yerbas, ó otros ingredientes, se dedican á curar dolencias y enfermedades. No les faltan Patronos y Protectores, á quienes un alivio casual, ó una curativa que resultó sin conocimiento fundado del artífice, sirve de antecedente para ponderar y dibulgar su avilidad y acierto. En las Repúblicas bien ordenadas se mira este punto con exrupulosidad. No se cierra totalmente la Puerta al conocimiento experimental aunque le falten principios de la Profesión Médica; pero no se permiten á todos los que se llaman curanderos, ni se les disimula el que se apliquen á querer sanar todas las dolencias. Los sugetos son examinados en su porte y conducta; y los Medicamentos, se reconocen por congeturar su congruencia, y si inducen malicia, y pueden ser notoriamente nocivos»102.
\end{abstract}

Es patente el eco de las polémicas españolas entre los «científicos» y los «prácticos» en campo médico, que ocuparon buena parte del siglo XVIII. Además, mientras que en general la opinión ilustrada dominante había ya dado por resuelta la polémica en favor de la «clínica empírica», encontramos rastros de las teorías «naturalísticas» en medicina que, en las últimas décadas del siglo, habían vuelto de manera nueva a interesar a algunos ambientes ilustrados (en Nápoles y Madrid, entre otros).

102 «Relación del Fiscal al Consejo de Indias sobre el pedido del Dr. Campins» (17 de enero 1777), AGI, Caracas, 241. 
El fiscal está convencido de la necesidad de un control institucional, pero a través de un cuidadoso examen del valor real del saber de los curanderos. En esto demuestra su concordancia con el análisis del gobernador, al cual impone no sólo la participacion en dichos exámenes, sino también la presidencia de la Junta examinadora. El intento del Fiscal parece ser el de disminuir el poder del futuro Protomédico sobre los curanderos y, por esto, impone una composición particular de la junta examinadora:

\footnotetext{
«...Dos Diputados del Cabildo Eclesiástico, y Secular, de algunos Prelados de las Religiones, del Rector de la Universidad y del Protomédico, la cual deberá presidir el Gobernador, que es o fuera de la referida Provincia, a quien impongo la obligación de darme cuenta de su resulta y circunstanciadamente de los médicos examinados que hubiera a la sazón» ${ }^{103}$.
}

El 14 de mayo de 1777 el Rey firma una Cédula verdaderamente original en el panorama de la historia de la medicina colonial latinoamericana ${ }^{104}$ : se autoriza la creación del Protomedicato, dándole todas las funciones que preveían las leyes de Indias, con la excepción específica de cuanto se refiere a los curanderos:

«He resuelto también que respecto de la escasez de Médicos que se insinúa haver en la
ciudad de Caracas se tolere por ahora la continuación de algunos de los curanderos que sean
más hábiles y de mejor conducta señalándolos y poniéndolos en lista, con examen y aproba-
ción de una Junta que para este fin se ha de componer...»105.

Creado así el Protomedicato y nombrado Campins como primer Protomédico, se trataba ahora de poner en práctica las indicaciones de la Real Cédula y llamar a examen a los curanderos. Las leyes de Indias atribuían a los protomédicos una jurisdicción de sólo cinco leguas alrededor de la ciudad sede del Tribunal. Podrían también entregar licencias de ejercer a los individuos de otras provincias que avanzaban por propia cuenta su petición (así pasó con un médico de Cumaná). Eran excluidos de la jurisdicción del Protomedicato los pueblos de indios. En este sentido, se puede afirmar que el área de acción de Campins se reduce a Caracas y a su extrarradio. Sin embargo, considerando la creación de la Capitanía General en el mismo año de 1777, con sede capital en Caracas, el cargo de Protomédico adquiría un valor mayor, aunque su jurisdicción legal continuaba siendo la misma.

En agosto de 1777 el Cabildo ratifica el nombramiento y Campins puede empezar a ejercer su nuevo cargo. Se forma la Junta que debía examinar a los curanderos y se

\footnotetext{
103 «Cédula Real que crea el Protomedicato en Caracas» (14 de mayo de 1777), AGI, Caracas, 317.

104 Cfr. ARCHILA (1961), p. 415.

105 «Cédula Real que crea el Protomedicato en Caracas» (14 de mayo de 1777), AGI, Caracas, 317.
} 


\section{CURANDEROS Y MÉDICOS ILUSTRADOS}

deciden los aranceles a pagar por las actividades del Protomedicato ${ }^{106}$. Sobre el tema de los curanderos, la Junta se reúne sólo en julio de 1778, presidida por el capitán general don Luis Unzaga y Amezaga, y constituida por representantes del Cabildo, de la iglesia, de la Universidad y, naturalmente, del doctor Campins, único médico de la Junta. Fueron llamados a examen catorce «curiosos»:

$\begin{aligned} \text { Juan de Crubes } & \text { Cirujano y curandero; } \\ \text { Luciano de la Santa } & \text { Curandero y boticario; } \\ \text { Santiago Francín } & \text { Cirujano; } \\ \text { Juan Polacro } & \text { Cirujano y curandero; } \\ \text { Don Thomas } & \text { Cirujano de la tropa; } \\ \text { Juan Castro } & (?) \\ \text { Joseph Sebastián Siso } & \text { Curandero y boticario; } \\ \text { Juan José de Torres } & (?) \\ \text { Domingo Esteban Fallegos } & (?) \\ \text { Miguel el Conde } & (?) \\ \text { Diego Mejías Bejarano } & (?) \\ \text { Martín Antonio Pereira } & (?) \\ \text { Juan de Combe } & \text { Cirujano y curandero; } \\ \text { Juan Nepomuceno Núñez } & (?)^{107} \text {. }\end{aligned}$

De éstos se presentaron sólo seis el 8 de julio de 1778 y fueron examinados por la Junta. Todavía no hemos encontrado la documentación inherente a estos exámenes y, por ahora, podemos solamente adelantar la hipótesis de que Campins utilizara las indicaciones generales de las Leyes de Indias (a las cuales había hecho amplia referencia en el momento de la petición al Rey) y de la «Pragmática» del 7 de noviembre de 1617, específica sobre el tema ${ }^{108}$. Esta imponía como requisito al examen dos años de práctica a los médicos y cirujanos e indicaba como materia del examen los siguientes temas:

«Que los Protomédicos ó Examinadores examinen a los que se vinieron á examinar, así Médicos como Cirujanos, por las doctrinas importantes de Hipócrates y Galeno, sin que tengan obligación de tomar de memoria las Instituciones á la letra, como hasta aquí se hacía: y que los Médicos sean examinados, pidiéndoles cuenta de las materias mas importantes; pri-

\footnotetext{
106 Cfr. ARCHILA (1961), p. 418.

107 Ibidem, pp. 297-98.

108 «Nuevo Método para el examen de Médicos, Cirujanos y Boticarios en el Protomedicato», en Rivero (1931), pp. 55-60. 
mero de la parte natural, y luego de la de fiebres, de locis affectis morbo et sinthomate, por la letra y exemplos que trae Galeno, y los libros de método desde el séptimo libro, y principalmente los de artibus, de urinis, pulsibus, sanguinis, minsione et expurgatione...»109.

A los cirujanos no se les pedía saber de memoria las «Instituciones», sino lo suficiente de «Álgebra», arte de componer los huesos, y demostrar haber practicado este «arte» con un «algebrista»110. No sabemos si los exámenes de los curanderos en Caracas siguieron estas indicaciones, aunque parece muy probable.

De los seis curanderos que se presentaron al examen, cuatro fueron aprobados como cirujanos romancistas y dos como médicos. De éstos, los dos médicos eran uno «pardo limpio» y el otro «pardo libre». Entre los cirujanos había también, por lo menos, un mulato ${ }^{111}$. Es interesante anotar que los curanderos aprobados no se presentaron a recoger los títulos respectivos y el Protomédico debió recurrir al capitán general para conminarles el retiro del título (marzo de 1779).

Los curanderos que no aceptaron ser examinados por el Protomédico continuaron su actividad, incluidas algunas mujeres que no habían sido llamadas a examen. Así pasó con el cirujano y curandero, Juan de Crubes; el curandero y boticario Luciano de la Santa; el curandero Juan José de Combe; etc ${ }^{112}$.

El caso del boticario José Sebastián Siso merece una mención particular. Se trataba de un «pardo libre», caraqueño, que había ejercido la medicina como ayudante del doctor Zuñier y administrador de su botica, ejerciendo con éxito como farmacéutico y médico. Parece que el gobernador Solano había utilizado con satisfacción sus servicios, nombrándole cirujano del Batallón de Pardos. Este boticario y curandero, una vez que la noticia de la creación del Protomedicato circuló por Caracas, se adelantó al llamamiento a examen del Protomedicato, apelando directamente al Rey para conseguir autorización de ejercicio en Caracas. Desde Madrid se autorizó su actividad interinamente, mientras que se organizaba el examen ${ }^{113}$. Sin embargo, incluido en la lista de curanderos llamados a examen, no se presentó, continuando su actividad. De cualquier manera, en el mismo 1778, el Protomédico, después de una inspección a la botica, le entregaba licencia para ejercer esa actividad farmacéutica ${ }^{114}$.

Campins tuvo también problemas, en el comienzo de sus actividades como Protomédico, con el curandero Gaspar Latouche que desconociendo su autoridad, consiguió del capitán general un título de cirujano y médico. Más dramático fue el caso de

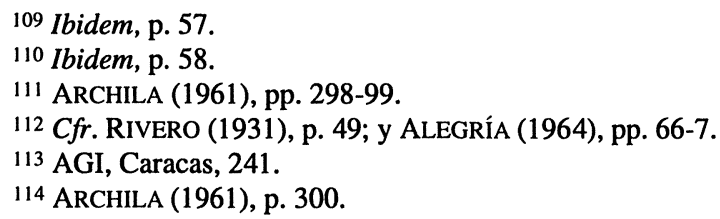


la curandera María Gregoria Ramos Casanueva. Como ya hemos visto, en Caracas había muchas curanderas que no fueron incluidas en la lista de Campins. Después de la institución del Protomedicato, Campins comenzó a prohibirles el ejercicio de la medicina. De una, por lo menos, sabemos que reaccionó violentamente, denunciando a su vez a Campins y alegando que tenía una experiencia de más de treinta años en la profesión y, además, no cobraba. En su defensa, la curandera Ramos presenta un cuadro realista de la medicina en Caracas:

\footnotetext{
«Si el doctor Campins hubiese fulminado mi causa con imparcialidad llevado del celo aparentado que nos pretende persuadir le impelió a ello, era indispensable que también hubiera levantado Auto a proceder contra otras muchas mujeres y aun señoras principales que no ignora se ejercitan públicamente tanto como yo en medicinar este o aquel enfermo por las razones y causales relacionadas y aun se vería en la necesidad de proceder contra toda la Ciudad porque cada cual en su casa regularmente medicina sus enfermos y apenas en un caso muy muy urgente se llama a un médico, que luego tratan de despedirlo por hacerse insufribles el costo de visitas y botica, y también porque las más veces no aprovechan sus recetas y vienen a mejorar los pacientes con los medicamentos que llaman caseros y con muchas yerbas medicinales de que abunda la Provincia»115.
}

De cualquier manera, el resultado de la creación del Protomedicato no fue muy grande, si consideramos todos estos problemas y que los curanderos continuaron, de una manera $u$ otra, ejerciendo. Otra tentativa para eliminarlos fue hecha en 1792 por el doctor Felipe Tamariz, alumno y sucesor de Campins. El ataque de Tamariz incluyó explícitamente a los curanderos dotados de títulos por el Protomédico en la epoca del examen (1778). En 1800, Tamariz presentó al Cabildo la propuesta de negar la licencia a los pardos argumentando que ya había suficientes médicos blancos para atender a la población; el Cabildo rechazó la propuesta considerando que todavía eran necesarios.

Los pocos médicos blancos, dictaminó el Cabildo, «...apenas podrían asistir con la atención necesaria a los enfermos de la clase de blancos y con suma dificultad a algunos de las clases inferiores que tengan facultad y quedando el resto de estas clases abandonado en sus enfermedades, no solamente por que no alcanzaran el tiempo y fuerzas de los médicos blancos a visitarlos, y curarlos, y porque la mayor parte son menesteres y jornales muy pobres que las más de las veces ni aún podrán pagar medio real por cada visita, sino también por que los médicos blancos no se acomodan bien al trato de los negros y zambos y mulatos...»116.

\footnotetext{
115 AGI, Caracas, 269.

116 AGNC, La Colonia, Títulos de Médicos, 1799-1806, Tomo 1, ff. 124-124 vto.
} 
Tenemos aquí, una vez más, la comprobación de la diferente actitud hacia la población menos favorecida entre el Cabildo de Caracas y los médicos universitarios. Después de varios pleitos, el doctor Tamariz consigue en 1809 que la Real Audiencia anulara la cédula de 1777 sobre la tolerancia de los curanderos y así pudo negar el ejercicio de la profesión médica a los pardos ${ }^{117}$. Una victoria final meramente simbólica, ya que el año siguiente comenzaría el proceso de Independencia venezolano, con la consecuente caída del orden jurídico español.

\section{CONCLUSIONES}

El caso que hemos analizado nos permite adelantar algunas consideraciones generales sobre la formación de las figuras médicas en América. Desde una situación relativamente confusa y ambigua, donde los «barberos» se confunden con los curanderos y los médicos titulados, se llega paulatinamente a una definición precisa de los ámbitos de acción de cada figura.

En el caso de Caracas, a lo largo del siglo XVIII, constatamos esta progresiva formación de la figura médica «clínica» a expensas de los curanderos (populares y, sobre todo, «cultos»). La institucionalización de la medicina permite a los médicos «producir» un control sobre los curanderos a través de la constitución de un «cuerpo» médico cerrado. De esto, en el fondo, se trata: el «cuerpo» institucional (del Estado) se impone como único gestor de los «cuerpos» de los ciudadanos, particularmente cuando la enfermedad «quiebra» el orden cultural de la salud.

Al mismo tiempo, y como condición de la operatividad del control, se impone un recorrido obligado para el aprendizaje de la medicina. A finales del siglo XVIII, en América como en Europa, ya no será posible aprender la profesión médica de manera individual y autónoma, asistiendo a un experto en sus prácticas cotidianas de curación. La producción del saber médico y su transmisión se realizará bajo el control de las instituciones autorizadas por el Estado. El «saber controlado» se impone sobre un «saber salvaje», autónomo y, por ende, subversivo.

El Protomedicato y, sobre todo, la Universidad se constituirán en el siglo XIX como único espacio para la elaboración del saber médico y la formación de los profesionales de salud. De esta manera, aquel «curanderismo» culto del siglo XVIII volverá a fundirse con las prácticas «médicas» populares y con las «mágicas», de las cuales había conseguido alejarse. Se eliminará, así, la ambigüedad semántica del término «curandero», separándose netamente los ámbitos de la acción médica (la

117 Cfr. ARChILA (1961), p. 316. 


\section{CURANDEROS Y MÉDICOS ILUSTRADOS}

«magia» y la «medicina»): en el siglo XIX, un curandero no será considerado médico, sino «brujo»y, en los mejores de los casos, «yerbatero».

Finalmente, en Caracas, a finales del siglo XVIII, se asiste a un intento de mantener activos a los curanderos, destinando su actividad a los estamentos más bajos de la sociedad local y reconociéndoles una función social y un saber médico no despreciable. Aun considerando que las razones explícitas para permitir de manera extraordinaria las prácticas curanderiles son de orden social y político («no hay médicos», «el pueblo los quiere», etc.), nos parece que el caso se inserta en un contexto mayor de debate intelectual. De hecho, a partir de las motivaciones que el Fiscal del Consejo de Indias aporta para justificar su decisión sobre el caso de los curanderos caraqueños, se puede considerar la polémica local en el marco de una más amplia entre la «medicina clínica» y la «medicina natural» que se desarrolló en Europa a finales del siglo XVIII. Es decir, la posibilidad de recorridos múltiples para la percepción y acción sobre la realidad, contra la rigidez de la «racionalidad» imperante.

Cuando en 1809 el doctor Felipe Tamariz consigue la anulación de la Cédula Real de 1777 (en la parte que se refiere a los curanderos), se cerrará este ultimo intento de mantener abiertas unas alternativas para la solución de las enfermedades y, aunque las guerras de Independencia mezclarán nuevamente las figuras médicas, la institucionalización de la profesión médica será ya un hecho realizado y faltará sólo organizarla en el nuevo Estado republicano. 